\title{
Assessment of parameters windows and tool pin profile on mechanical property and microstructural morphology of FSWed AA2014 joints
}

\author{
Jayashree $\operatorname{Das}^{1} \cdot$ P. Sreedharan Robi ${ }^{1}$ Mamilla Ravi Sankar ${ }^{1,2}$
}

Received: 12 November 2019 / Accepted: 11 December 2019 / Published online: 20 December 2019

(c) Springer Nature Switzerland AG 2019

\begin{abstract}
The role of optimized parameters in deciding the qualities of the friction stir welded joint of 2014 aluminium alloy in terms of the mechanical properties and microstructural features was investigated in this research. A wide range of process parameters viz: tool shoulder diameter, tool pin profile, plunge depth, tool rotation speed and welding speed were selected and their individual effects on the tensile as well as microstructural properties variations were studied in detail. Out of four various selected tool pin profiles the excellent mechanical as well as microstructural properties of the square pin (SQ) tool are due to the unique stirring effect by the pulsating action of the sharp edge of the pin and metal propagation process at the stir area with incorporation with the tool rotation as well as welding speed during the friction stir welding. The SQ pin tool of $24 \mathrm{~mm}$ shoulder diameter with a plunge depth of $0.06 \mathrm{~mm}$ and tool rotating at $815 \mathrm{rev} / \mathrm{mm}$ with welding performed at a speed of $63 \mathrm{~mm} / \mathrm{min}$ yielded the best quality joint. The ultimate tensile strength is around $86 \%$ of the base metal (BM) with excellent metallurgical characteristics contributed by the $84 \%$ finer grains than the $\mathrm{BM}$ ensured from the detail microstructural analysis of the weld bead. The metallurgical study includes the variations in the grain size at the nugget zone with respect to the selected process parameters as well. Fractography of the welded specimen reveals a ductile and transgranular mode with cup and cone structures on the counterpart.
\end{abstract}

Keywords Friction stir welding · Aluminium alloy · Process parameters · Mechanical property · Fractography · Macro and microstructural characterization

\section{Introduction}

Friction stir welding (FSW) method is a revolutionary process in solid form joining procedure invented at The Welding Institute by Thomas et al. [1]. Being a solid form joining process, the FSW process has a numerous technical advantages, for example, high production rate, smooth weld bead surface, environment-friendly, fewer residual stress and distortion compared to the conventional fusion welding process. The process has brought a metamorphosis in the standard of welding in difficult-to-weld materials like aluminium (Al) and its alloys which are difficult to join through fusion welding process [2] and produces satisfactory mechanical properties. Aluminium and its alloy are widely applied in aviation, aeronautical structure panels [3] automotive and shipbuilding and many other industries. The demand for weight reduction, fuel consumption and cost in the aerospace industry can be fulfilled by the FSW process. FSW is a solid-state, less energy consuming and repeatable metal fabrication process capable of producing high strength joints, offers a potentially lower cost and is environment-friendly [4]. The high strength 2014 aluminum alloys are extensively applied in aircraft structures and are prone to solidification cracking, void

P. Sreedharan Robi, psr@iitg.ernet.in | Department of Mechanical Engineering, Indian Institute of Technology Guwahati, Guwahati, Assam 781039, India. ' Department of Mechanical Engineering, Indian Institute of Technology Tirupati, Tirupati, Andhra Pradesh 517506, India. 
generation and dissolution of hardening precipitates welded by conventional fusion welding processes and are inferior in mechanical properties reported in $[5,6]$. These difficulties can be solved by the FSW process which has key benefits over fusion welding methods [7]. The FSW process yields less distortion of the workpiece, excellent metallurgical properties of joint, more reproducible properties, without shielding gas and surface cleaning requirement, etc., as the joint is fabricated by only plasticizing the metal by the rotating tool and advancement of the tool in welding direction [8]. The plasticized material flow behaviour and the factors which influence it are mainly the tool shoulder diameter, plunge depth, pin profile of the tool and the tool rotation as well as welding speed that affect the quality of the FSW joint. This investigation aims to find out the mechanical attributes of the friction stir welded (FSWed) joint of AA2014 welded with different considered parameters.

The microstructure and mechanical qualities of the FSW joints of AA2139-T8 and AA7020-T651 were studied and corelated to the welding parameters viz; the rotation and welding speeds with the total and local mechanical behaviors and found that the joint hardly failed at the nugget zone (NZ) and most of the specimens failed at the heat affected zone (HAZ) which exhibited the lower hardness history due to the faster coarsening of $\eta$-precipitates present in the matrix [9]. The tensile behaviour and corrosion resistance of AA2014 aluminium alloy FSWed at seven different speed combinations and found that the highest temperature was achieved at higher tool rotation speed and lower welding speed. Microhardness and corrosion resistance were found to be the best at low rotation speed and high traverse speed [10]. The influences of various tools with a high ratio of depth-to-width on weld quality, hardness, grain structure, as well as crystallographic texture in the FSW process were also studied in [11, 12]. In the FSW of AA2198/AA2024, it is realized that the parameter tool traverse speed when increased the over-all hardness of the joint is increased and kissing bond defects are formed [13]. In the FSW of AA2219-T6, it is possible to fabricate higher quality weld at much more higher speeds by hybrid tool pin profile without any harm to the tool pin than the conventional conical threaded tool [14]. The mechanical and microstructural characteristics of both similar and dissimilar FSWed sheets of AA2219 and AA7475 AA were investigated and found that at considered process parameters of rotation speed, welding speed and tool tilt angle, grain refinement was observed at the NZ. The dissimilar metal FWS joint exhibited poor tensile strength due to improper metal transfer during welding. The retreating side of the thermo-mechanical affected zone (TMAZ) showed the lowest microhardness history due to thermal softening [15]. During the FSW process heat generated by the tool due to friction has a remarkable effect in reducing hardness, heat affected area and its distance from the weld centre were studied in $[16,17]$. Research on the effect of process parameters considered viz: tool rotation speed, welding speed, axial load and the shoulder to pin diameter ratio (D/d) for AA2024-T6 and AA7075-T6 in dissimilar FSW was carried out and found that $(D / d)$ ratio affect the mechanical and microstructural features the most [18]. The hardness variation at constant rotation and different welding speed of FSWed dissimilar joints of $\mathrm{Mg}-\mathrm{Zn}-\mathrm{Gd}$ and $\mathrm{Mg}-\mathrm{Al}-\mathrm{Zn}$ alloys were carried out and observed that the tensile properties of the joints are significantly influenced by the material's positions, grain size and crystallographic orientation. Defects rose at lower heat input conditions due to insufficient metal plasticization [19]. In FSW of AA2024 researchers can produce excellent quality weld by scroll shoulder and tri-flute pin at high welding speed. The welds achieved were defect-free and with a good ductility [20]. The consequence of different process parameters along with the tool pin design chosen for the experiment on the mechanical aspects of AA 2014-T6 was studied and found that the quality of weld achieved by hexagonal tool pin profile was superior to the conical one [5]. In dissimilar FSW of Ti-6Al-4V/AA6061, the effect of the most important process parameter, rotational speed on the mechanism of bonding at the interface is investigated and observed that the tensile properties and microhardness are increased due to the recrystallization process. The tool rotational speed causes the formation of the intermetallic at the joint line [21].

The aforementioned literature survey discovers the scarcity in the study of process parameters in a wide spectrum in single literature. It is understood that deep research is required to find the effect of different process parameters on material flow behaviour during FSW and microstructural evolution at the NZ of the FSWed AA 2014. There is a limited work regarding the impact of plunge depth and tool pin profile effect on the weld value. The information related to the flexural strength (FS) of FSWed AA2014 with different process parameters is very scant. Microhardness variation at the three different zones of the welded specimen such as upper, middle and bottom as well as the role of process parameters on the grain structure at the NZ and the influence of grain size variation on mechanical properties are still not studied. In this research work, the lacuna is filled and a detail investigation of the process parameters and their role in regulating the mechanical properties has been carried out.

\section{Experimental procedure}

AA2014 was the base material (BM) for this investigation with chemical composition $\mathrm{Cu}: 3.9-5 \%$, Fe: $0.7 \%$, Mn: $0.4-1.2 \%$, Mg: $0.2-0.8 \%, C r: 0.1 \%$, Si: $0.5-1.2 \%$, Ti: 
$0.15 \%, \mathrm{Zn}: 0.25 \%$ with balance $\mathrm{Al}$ in weight percentage. Mechanical properties of the BM as per the ASTM standard are shown in Table 1. A vertical milling machine of knee-type having a series of tool rotational speeds (50 to $1500 \mathrm{rev} / \mathrm{min}$ in $12 \mathrm{steps}$ ) and welding speeds ( 22 to $550 \mathrm{~mm} / \mathrm{min}$ in 8 steps) was used for the experiment. Different designed FSW tools of $\mathrm{H} 13$ tool steel with a pin length of $5.6 \mathrm{~mm}$ (decided according to the plate thickness) were used for this process as shown in Fig. 1. The $100 \mathrm{~mm} \times 100 \mathrm{~mm} \times 6 \mathrm{~mm}$ dimension plates were welded by using FSW set up in the rolling direction in a single pass butt joint configuration. They were edge prepared to obtain nearly zero gaps and the surface was cleaned by acetone to avoid any chance of defect in the welds due to foreign particle. Tool shoulder diameter, the profile of the tool pin, plunge depth, tool rotation speed as well as welding speed presented in Table 2 were selected as the process parameters. For each considered process parameter, three experiments were done to inspect the repeatability and from the result of repeated experiments very negligible variation was found.

The tensile test, flexural test, three-point bending test, microhardness test, and metallographic tests were performed on the respective specimens as shown in Fig. 2 extracted from the welded plates to judge the joint qualities. Average ultimate tensile strength (UTS), yield strength
Table 1 Mechanical attributes of the base material

\begin{tabular}{lllllll}
\hline Property & YS (MPa) & UTS (MPa) & $\% \mathrm{E}$ & FS (MPa) & Bending angle $\left({ }^{\circ}\right)$ & Hardness (HV) \\
\hline Value & 350 & 460 & 13 & 545 & 140 & 105 \\
\hline
\end{tabular}

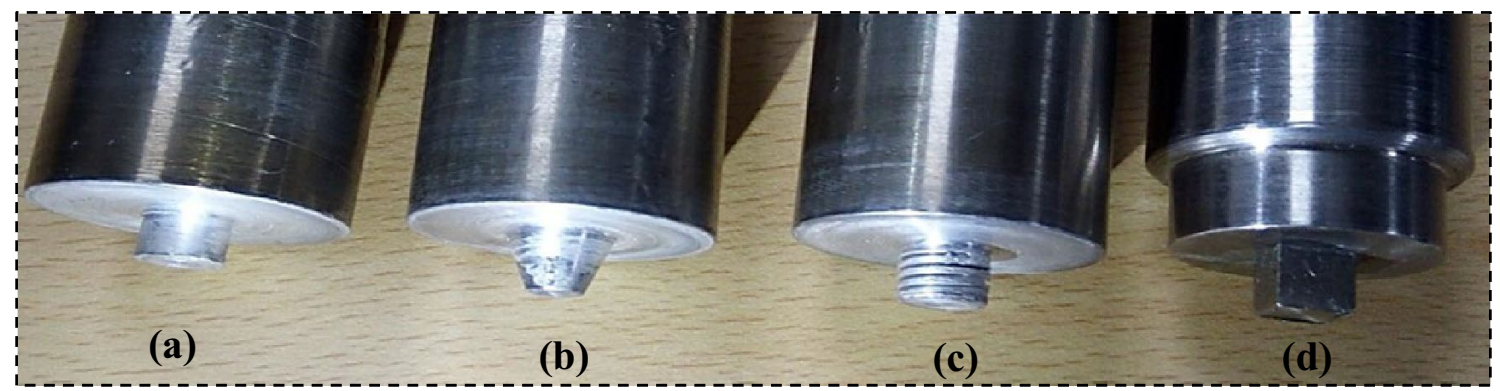

Fig. 1 Tools used for FSW process a straight cylindrical (STC), b tapered cylindrical (TAC), c threaded cylindrical (THC), d square (SQ)

Table 2 Experiments conducted with different process parameter combinations

\begin{tabular}{|c|c|c|c|c|c|}
\hline Exp. no & $\begin{array}{l}\text { Shoulder diam- } \\
\text { eter }(\mathrm{mm})\end{array}$ & $\begin{array}{l}\text { Plunge } \\
\text { depth (mm) }\end{array}$ & Tool pin profile & $\begin{array}{l}\text { Tool rotation } \\
\text { speed (rev/min) }\end{array}$ & $\begin{array}{l}\text { Welding } \\
\text { speed ( } \mathrm{mm} / \\
\text { min) }\end{array}$ \\
\hline E1 & 16 & 0.03 & Straight cylindrical & 600 & 22 \\
\hline E2 & 20 & & & & \\
\hline E3 & 24 & & & & \\
\hline E4 & 28 & & & & \\
\hline E5 & 24 & 0.06 & Straight cylindrical & 600 & 22 \\
\hline E6 & & 0.09 & & & \\
\hline E7 & & 0.12 & & & \\
\hline E8 & 24 & 0.06 & Tapered cylindrical & 600 & 22 \\
\hline E9 & & & Threaded cylindrical & & \\
\hline E10 & & & Square & & \\
\hline E11 & 24 & 0.06 & Square & 815 & 22 \\
\hline E12 & & & & 1100 & \\
\hline E13 & & & & 1500 & \\
\hline E14 & 24 & 0.06 & Square & 815 & 36 \\
\hline E15 & & & & & 63 \\
\hline E16 & & & & & 98 \\
\hline
\end{tabular}




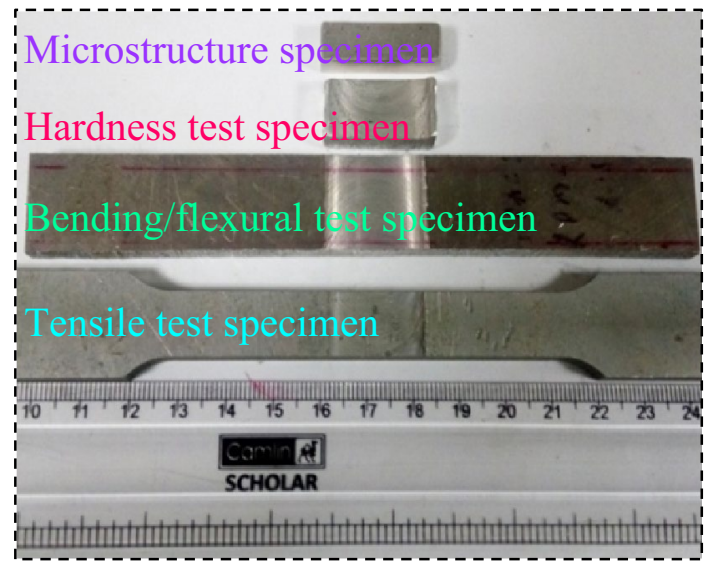

Fig. 2 Different test specimens extracted from the welded plates

(YS), percentage elongation (\%E), bending angle, flexural strength (FS), hardness at different zones (HV), macro as well as microstructure were studied. Tensile tests were executed on a standard ASTM E8M-04 specimen by a hydraulically operated servo-controlled dynamic universal testing machine (UTM) (INSTRON; 8801). The \%E was measured by using an extensometer of $50 \mathrm{~mm}$ gauge length connected to the specimen during the tensile test. By a 3-point bending tester set up compatible with the UTM machine, bending angle and FS were measured. Microhardness was measured by Vickers micro-hardness machine at $500 \mathrm{~g}$ load for $10 \mathrm{~s}$ across the HAZ, TMAZ, NZ as well as the BM. The cracked faces of the tensile tested specimen were analyzed by using field emission scanning electron microscope (FESEM). The metallographic study was done at the respective weld zones after polishing the specimen by coarser to finer grades of emery papers followed by velvet cloth polishing. To observe bead geometry, grain distribution and variation in the grain size with different process parameters at a varying magnification at considered weld zones through the optical microscope, (make: Carl Zeiss, Model: Axiotech) the specimens were prepared by etching with modified Keller's reagent.

\section{Results and discussion}

The weld quality can be judged by the output of mechanical and metallurgical quality attributes. In this section, tensile properties, FS, bend angle, maximum hardness at NZ were studied along with the metallurgical analysis like the grain size at different weld zones and variation of the same with respect to different combinations of the considered process parameters like tool shoulder diameter, plunge depth, tool pin profile, rotation and welding speed of the tool. The correlations of grain size at NZ with the output mechanical properties were established. The present investigation was concluded with the fractograph analysis of the tensile fractured specimens.

\subsection{Tensile properties and flexural strength analysis}

Tensile tests were performed on the specimen welded with different process parameters as shown in Fig. 3 as well as on the BM to compare the quality of the weld. Each specimen broke at different locations depending on the superiority of the joint. Most of the specimens failed at the retreating side of the joint. Fracture is seen outside the welded zones as in Fig. 3a-c for the proper joint in case of experiment E10, E11 and E15. The specimen was broken at the $\mathrm{HAZ}$ represented in Fig. $3 \mathrm{~d}$ because of microstructural change and grain size variation between $B M$ and $H A Z$ in case of experiment E3. In Fig. 3e the fracture was noticed at the NZ in case of E1 for improper joint due to insufficient frictional heat generation and fracture occurred at TMAZ/HAZ interface as in Fig. $3 \mathrm{f}$ in case of $\mathrm{E} 2$ for the same reason as for E1. The UTS and YS of the best specimens are $393.87 \mathrm{MPa}$ and $282 \mathrm{MPa}$ and are $86 \%$ and $80 \%$ of the $\mathrm{BM}$ respectively. A comparison in the tensile properties of the BM with the specimen E15 is shown in Fig. 4a. The graph represents the failure of the welded specimen after the yield point, which is not a pure ductile failure but a mixture of ductile as well as brittle fracture and will be analyzed in the fractograph analysis later. The UTS, YS, \%E, FS, bending angle and hardness at the NZ of the welds were studied and are represented in Table 3. From table it was found that weld qualities of the specimens were inferior to the BM. The deterioration in properties is because of the softening of the metal or dissolution of precipitation

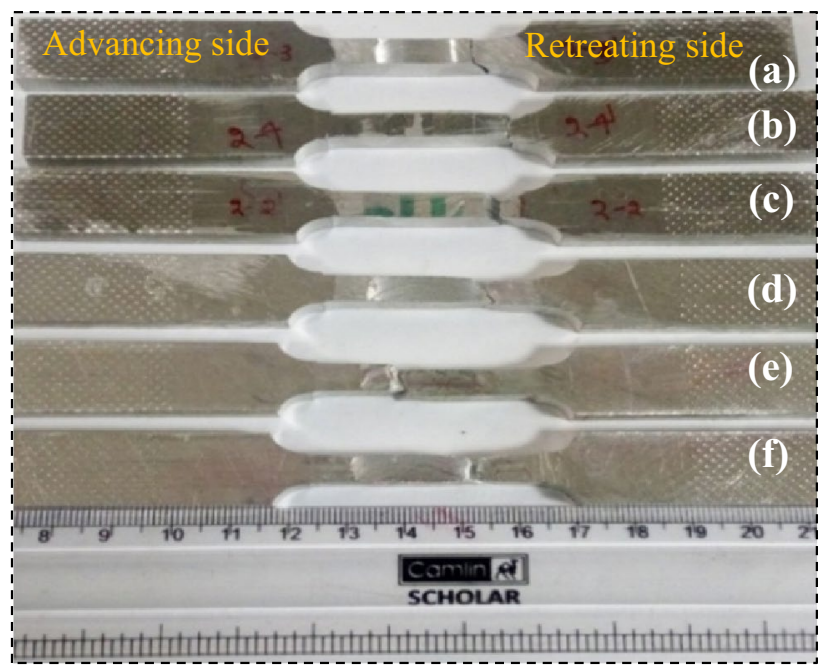

Fig. 3 Tensile tested specimens 

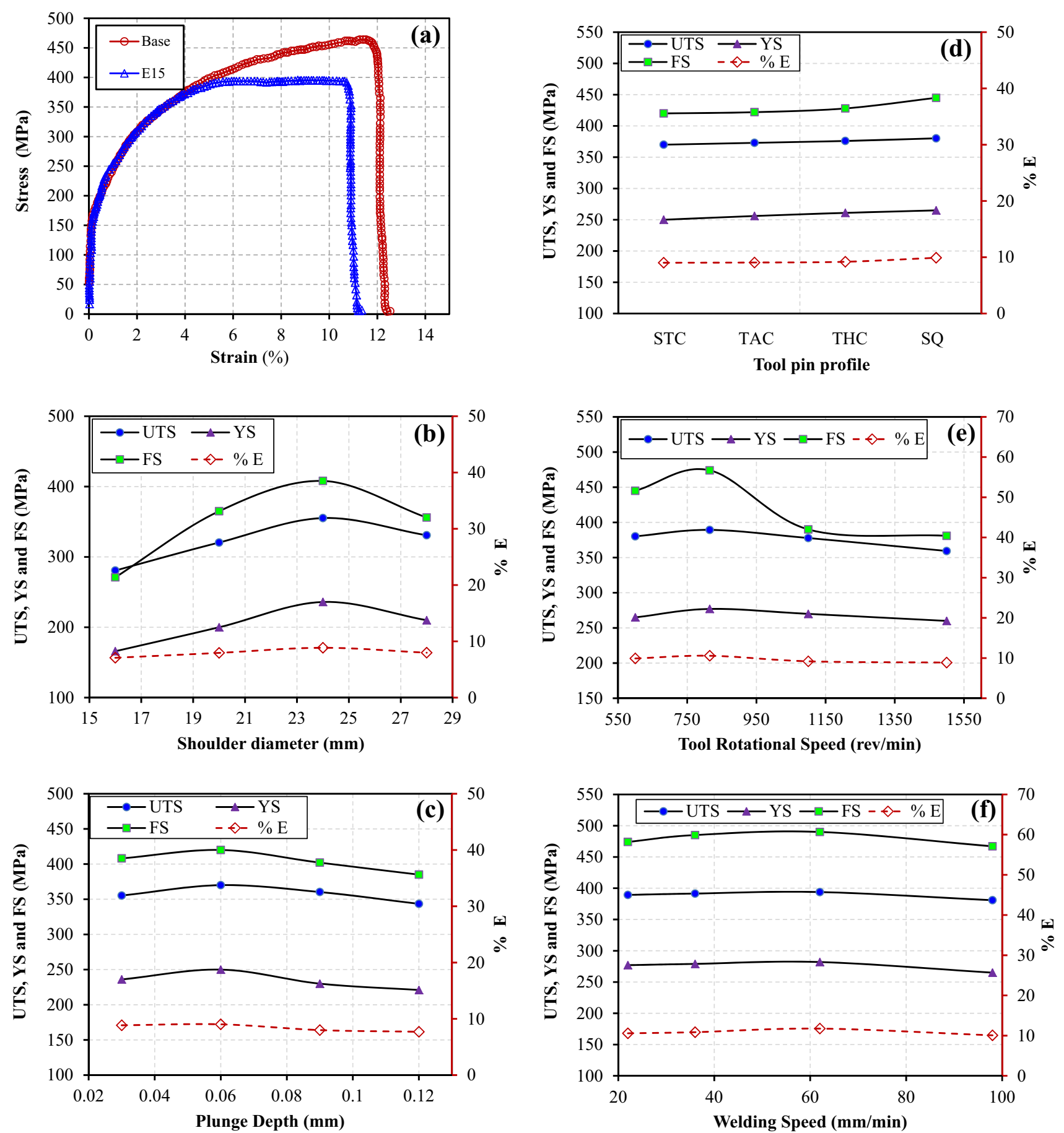

Fig. 4 a Stress versus strain curve of E15 with base material, UTS, YS, \%E and FS variation with (b) shoulder diameter, c plunge depth, $\mathbf{d}$ tool pin profile, $\mathbf{e}$ tool rotational speed and $\mathbf{f}$ welding speed

hardening material due to the FSW process as it happened in different heat treatable AA [22]. The extent of softening affects the tensile properties of the FSWed joint and is a function of process parameters shown in Fig. $4 b-f$.

The impact of the shoulder diameter on weld qualities is depicted in Fig. 4b. The graph represents that the tensile properties increase with an increase in diameter of shoulder from 16 to $24 \mathrm{~mm}$ and then deteriorate at shoulder diameter $28 \mathrm{~mm}$. At a lower shoulder diameter, the shoulder-workpiece rubbing surface is less which produces lower frictional heat to be conducted by the material to get plasticized. The inadequate frictional heat generated is 
Table 3 Mechanical properties of joints with various process parameters

\begin{tabular}{llllllll}
\hline Exp. no & UTS (MPa) & YS (MPa) & $\%$ E & FS (MPa) & $\begin{array}{l}\text { Bending } \\
\text { angle }\left({ }^{\circ}\right)\end{array}$ & $\begin{array}{l}\text { Hardness at } \\
\text { NZ }(\mathrm{HV})\end{array}$ & $\begin{array}{l}\text { Grain size } \\
\text { of NZ } \\
(\mu \mathrm{m})\end{array}$ \\
\hline E1 & 280.67 & 166 & 7.08 & 271 & 120 & 136 & 27 \\
E2 & 320.48 & 200 & 7.95 & 365 & 130 & 141 & 26 \\
E3 & 355.23 & 236 & 8.86 & 408 & 135 & 146 & 23 \\
E4 & 330.77 & 210 & 7.98 & 356 & 130 & 139 & 32 \\
E5 & 370.05 & 250 & 9.03 & 420 & 135 & 148 & 21 \\
E6 & 360.24 & 230 & 8.00 & 402 & 120 & 140 & 24 \\
E7 & 343.42 & 221 & 7.71 & 385 & 115 & 141 & 30 \\
E8 & 372.98 & 256 & 9.07 & 422 & 130 & 151 & 25 \\
E9 & 375.99 & 261 & 9.20 & 428 & 135 & 153 & 20 \\
E10 & 380.22 & 265 & 9.91 & 445 & 140 & 155 & 18 \\
E11 & 389.34 & 277 & 10.58 & 474 & 140 & 158 & 17 \\
E12 & 377.78 & 270 & 9.20 & 390 & 130 & 153 & 28 \\
E13 & 359.34 & 260 & 8.89 & 381 & 120 & 150 & 31 \\
E14 & 391.45 & 279 & 10.86 & 485 & 140 & 160 & 16 \\
E15 & 393.87 & 282 & 11.75 & 490 & 140 & 165 & 15 \\
E16 & 380.84 & 265 & 10.08 & 467 & 130 & 149 & 25 \\
\hline
\end{tabular}

not able to bring the metal to the desired level of plasticity for the proper mixing and filling to fabricate the joint [15]. Hence, the tensile properties achieved were inferior. A fall in tensile properties was also recorded at diameter $28 \mathrm{~mm}$ for the local thinning effect of the weld area due to more frictional heat generation. The best tensile properties were achieved at a shoulder diameter of $24 \mathrm{~mm}$ due to the suitable contact surface of the shoulder and adequate heat generation and transfer to the material below the shoulder for proper softening and interlocking to form the joint. The UTS, YS and \%E of the joint are 355.23 MPa, 236 MPa and 8.86 which are $77 \%, 67.4 \%$ and $68.15 \%$ of the $\mathrm{BM}$ respectively. More heat was generated and better weld was formed when the contact area is more. But when the contact area is too more i.e. at $28 \mathrm{~mm}$ shoulder diameter, the heat generated is more which makes the material softer and flowable and will be removed as an extra flash from the surface and results in to tear line defect. Also, a more contact area leads to the formation of wider TMAZ and $\mathrm{HAZ}$ and grain growth at the NZ due to extra heat input which resultantly deteriorates the tensile strength of the final weld [18]. For less than $16 \mathrm{~mm}$ shoulder diameter, the heat generated is not enough for the material to achieve the preferred plasticity to get intimately mixed during the welding and recrystallization process at the NZ was not satisfactory resulting in low quality welds observed from the trial experiments. So the welds performed only from 16 to $28 \mathrm{~mm}$ shoulder diameters are only considered for the present study. The flexural properties and bending angle were also analyzed for the joint with the same process parameters. The effect of the shoulder diameter on FS was investigated and observed that the trend is similar to followed by the tensile properties shown in the same Fig. $4 \mathrm{~b}$. FS is improved up to a shoulder diameter of $24 \mathrm{~mm}$ and is $408 \mathrm{MPa}$ and around $75 \%$ of the BM due to the proper heat generation and recrystallization of the grains at NZ and then degraded at a higher shoulder diameter for the grain coarsening due to unnecessary heat generation and grain growth [23].

Plunge depth is an important process parameter which regulates the final quality of the weld. There is a limited research article revealing the weld quality related to plunge depth. The plunge depth maintains the surface contact of the shoulder surface and base plate to transfer the frictional heat generated during the repeated rubbing of the shoulder on the workpiece [24]. It regulates the grain refinement and the microstructural evolution at the welded area and so affects the qualities of the final product. From the present experimental conditions, the best tensile properties with respect to the plunge depth were achieved at $0.06 \mathrm{~mm}$ shown in Fig. 4c. There is a sharp decrease in the same with an increase in plunge depth which reduces the volume of the weld. The UTS, YS, \%E and FS attained for the considered plunge depth are $370.05 \mathrm{MPa}, 250 \mathrm{MPa}, 9.03$, and $420 \mathrm{MPa}$ respectively, which are $80.45 \%, 71.40 \%, 69.50 \%$, and $77 \%$ of the BM respectively. Tensile properties and $\mathrm{FS}$ are inferior at both less and more than the accepted value i.e. at $0.03 \mathrm{~mm}$, at $0.09 \mathrm{~mm}$, and $0.12 \mathrm{~mm}$ respectively. Low quality of the weld at lower plunge depth is due to the improper surface contact which transfers less frictional heat. At more plunge depth, due to more insertion of the shoulder on 
the workpiece surface, a volume of the material from the weld surface was trimmed out and induction of stress concentration at the NZ occurs [7].

The selected profile of the tool pin for the experiment is another key parameter controlling the tensile properties and FS to large extent. The tool pin profile affects the turbulent flow of the softened material, the pattern of material impose and hence manages the plastic deformation. The material filling effect during FSW due to the various tool pin profile is represented in Fig. 5a-d. The welds with tool profile STC and TAC with volumetric tunnel defects observed at the NZ i.e. at the lower corner of the tool pin in continuous and non-continuous forms are shown in Fig. 5a, b. The defects disrupted the plastic metal filling during the joining process and degraded the quality of the welded joint due to the stress intensity factor [25]. Very small pores were noticed in the welded zone with THC pin profile as shown in Fig. $5 \mathrm{c}$ which affects the microstructural evolution and hence the quality of the FSW joints. The welds obtained were defect free in case of SQ tool pin profile as shown in Fig. $5 d$ due to its unique pulsating action on the plastic metal [25] and a superb metal interlocking during welding.
The weld quality in terms of tensile properties and FS obtained from four different tool pins such as STC, TAC, THC and SQ as shown in Fig. 1 are represented in Fig. 4d. The SQ pin tool is found to yield the best tensile results as compared to the others. The $\% \mathrm{E}$ and FS of the joint are also improved. The flat edge surface of the tool pin profile generates more frictional heat relative to the others with the same input energy. The plasticized metal gets swirled beneath the tool pin and the edges of the SQ pin tool pulsate the material in a regular manner and due to which an imposed plastic deformation takes place with fine recrystallized grains, which is the main cause of a defectless joint with improvement in tensile, flexural as well as microstructural properties [25]. SQ pin tool is better than the others in yielding superb mechanical as well as microstructural properties due to the plastically deformed and dynamically recrystallized grains at NZ [24]. The UTS, YS, $\% \mathrm{E}$ and $\mathrm{FS}$ achieved are $380.22 \mathrm{MPa}, 265 \mathrm{MPa}, 9.91$, and $445 \mathrm{MPa}$ respectively, and are $82.65 \%, 75.71 \%, 76.23 \%$ and $81.65 \%$ of BM respectively.

The effect of tool rotational speeds in different ranges such as $600,815,1100$ and $1500 \mathrm{rev} / \mathrm{min}$ and welding speeds varying from $22,36,63$ and $98 \mathrm{~mm} / \mathrm{min}$, on the
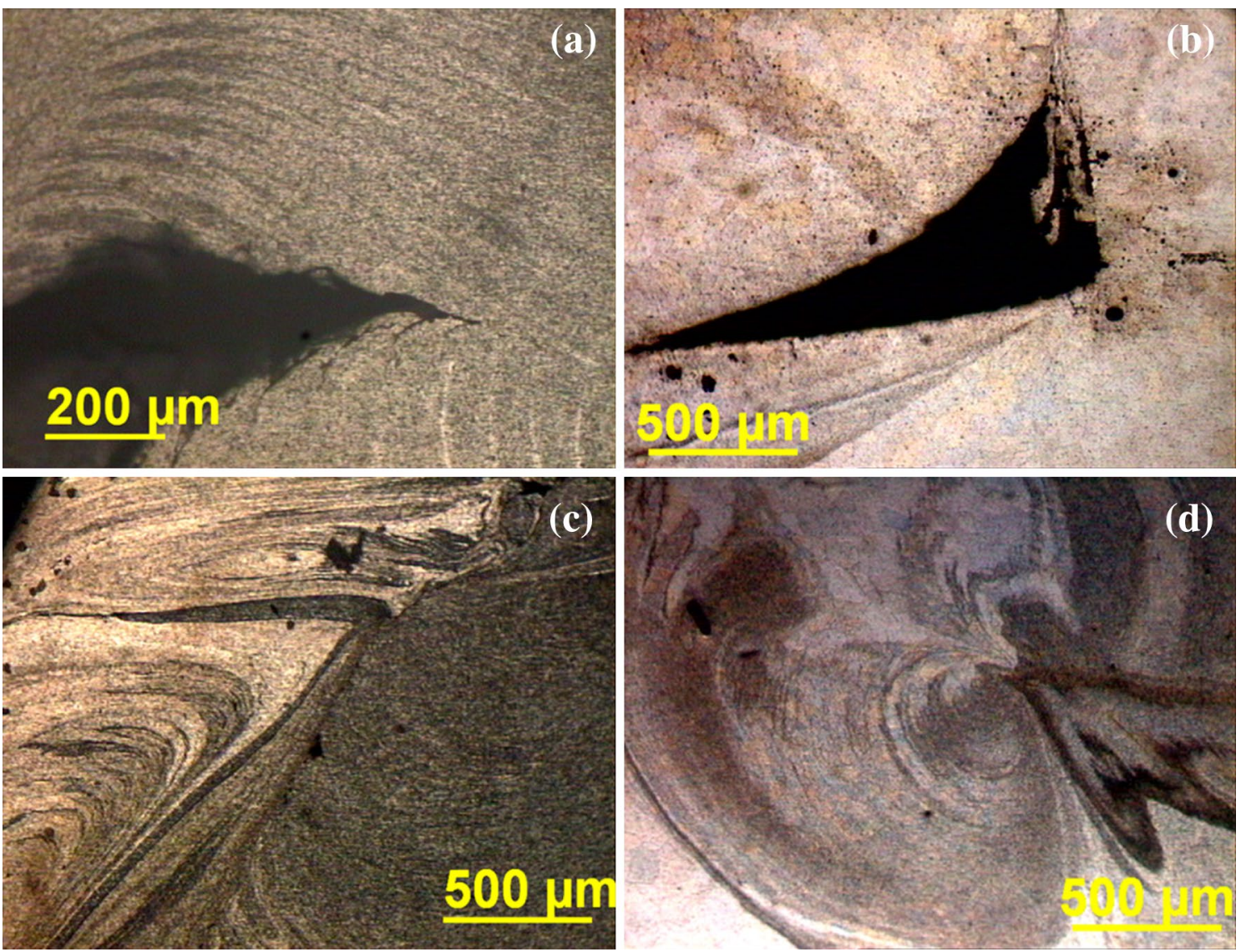

Fig. 5 Tunnel defect in a STC, b TAC, c minute pores in THC, $\mathbf{d}$ defect free in SQ 
weld quality were investigated and represented in Fig. 4e, f. The UTS, YS, \%E and FS are found to follow an increasing path with an increase in these two process parameters and finally trace a fall in the trend. From the experimental results of considered tool rotational speeds as shown in Fig. $4 \mathrm{e}$, the best weld quality is achieved at a tool rotation speed of $815 \mathrm{rev} / \mathrm{min}$ and the quality was deteriorated at $1100 \mathrm{rev} / \mathrm{min}$ and $1500 \mathrm{rev} / \mathrm{min}$. At high tool rotation speed, excessive frictional heat was generated and was contributed to the unwanted grain growth at the NZ and makes the weld inferior. Also at tool rotational speed more than $1000 \mathrm{rev} / \mathrm{min}$, the properties are degraded due to the disintegration and dissolution of the strengthening precipitates [26]. So the graph follows a decreasing trend. Also due to more frictional heat, the metal became more plastic and is removed from the surface in combination with the high centrifugal force [27] generated due to the high tool rotational speed. So the weld metal volume is reduced and voids like the tunnel and micro pores in the $\mathrm{NZ}$ are produced which reduces the tensile as well as FS of the welded joint. Hence at a tool rotational speed of 815 $\mathrm{rev} / \mathrm{min}$, the best tensile, as well as flexural properties are obtained. The UTS, YS, \%E and FS achieved are $389.34 \mathrm{MPa}$, $277 \mathrm{MPa}, 10.58$, and $474 \mathrm{MPa}$ respectively, and are $84.63 \%$, $79.14 \%, 81.38 \%$, and $87 \%$ of the BM respectively.

Considering the tool rotation speed and other process parameters constant, higher welding speed has shorter exposure time to the welded area which results in a noticeable decrease in heat input per unit length. So the plasticization is poor and material stirring and filling is inferior. Improper plasticization and material transfer result in weld defects like micro voids which lessens the tensile strength. At lower welding speed, the tool pitch travel distance is less and finer grains are formed due to proper plastic deformation and refinement for adequate frictional heat transfer. At a condition of very low welding speed, the heat input is very large and cooling rates are slower, so an excessive grain growth occurs which degraded the weld strength and hence the tensile and flexural properties are degraded studied in $[3,28]$. For the present experimental condition, the welding speed of $63 \mathrm{~mm} / \mathrm{min}$ yields the best mechanical as well as microstructural properties as shown in Fig. $4 \mathrm{f}$ due to smaller grains and more packing at NZ. The UTS, YS, \%E and FS achieved are $393.87 \mathrm{MPa}$, $282 \mathrm{MPa}, 11.75$, and $490 \mathrm{MPa}$ respectively, and are $86 \%$, $80.57 \%, 90.4 \%$, and $90 \%$ of the BM respectively. The face and root bending experiments were done on the welded specimen in the UTM as shown in Fig. 6 and for the sound welded specimen; the bend angle obtained is $140^{\circ}$. The bending angle for the best combination of process parameters of E15 is restricted up to $140^{\circ}$ without any visible crack for the limitation of the machine and may go up to $180^{\circ}$. From the above mechanical study, it is summarized

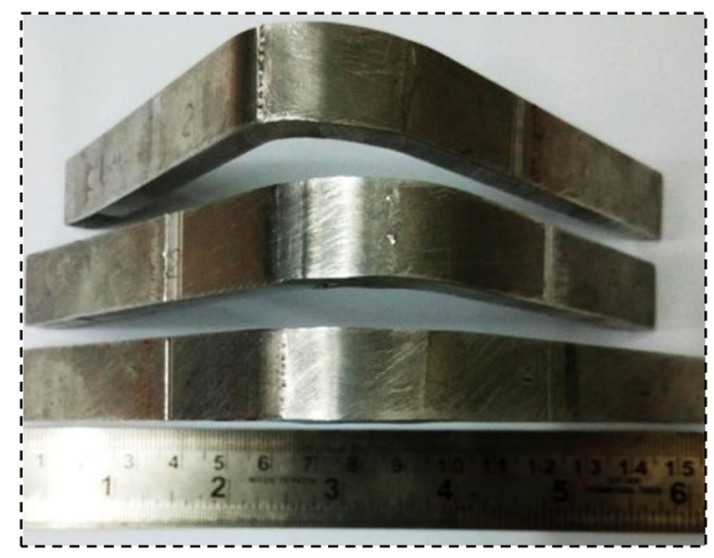

Fig. 6 Bending tested specimen

that the experiment E15 with association of process parameters such as the SQ tool pin profile with a $24 \mathrm{~mm}$ shoulder diameter at a plunge depth of $0.06 \mathrm{~mm}$, at a tool rotational speed of $815 \mathrm{rev} / \mathrm{min}$ and welding speed of $63 \mathrm{~mm} / \mathrm{min}$ yielded the best joint quality.

\subsection{Micro-hardness variation and relationship with process parameters}

A comprehensive study of the micro-hardness variation with the variation of welding parameters was performed in this section. Along with the cross-sectional thickness of the joint at three consecutive zones viz. the lowest, middle and upper the microhardness values of the welded specimen were measured and shown in Fig. 7a. At NZ the points were assessed at $1 \mathrm{~mm}$ gap and in other zones at $2 \mathrm{~mm}$ gap. The microhardness profile of the specimen $\mathrm{E} 15$ is revealed in Fig. $7 \mathrm{~b}$ and was found that the upper zone hardness is more than the other two due to the regular rubbing action of the shoulder surface on the workpiece which leads to plastic deformation and further grain refinement evidenced in Fig. 9a and increase in the hardness at any process parameters chosen. The NZ represents a better hardness due to the dynamic recrystallization for the proper stirring process of the tool than the other welded zones as well as the BM due to finer grain size where Hall-Petch law [29] is obeyed. The TMAZ represents a comparatively lower hardness as the strengthening precipitates are dissolved and less stirring influence of the tool pin during the welding process [30]. HAZ shows an inferior hardness for bigger grains due to grain growth where a zero stirring effect of the tool exists.

In Fig. 8a the effect of the shoulder diameter on hardness value is shown. Higher shoulder diameter helps in generating more heat on the workpiece which leads to better softening of the metal and proper mixing during stirring. As a result of which the grains became finer and 
Fig. 7 a Hardness indentation of the tested specimen, $\mathbf{b}$ hardness value at the upper, middle and bottom surface of the specimen E15

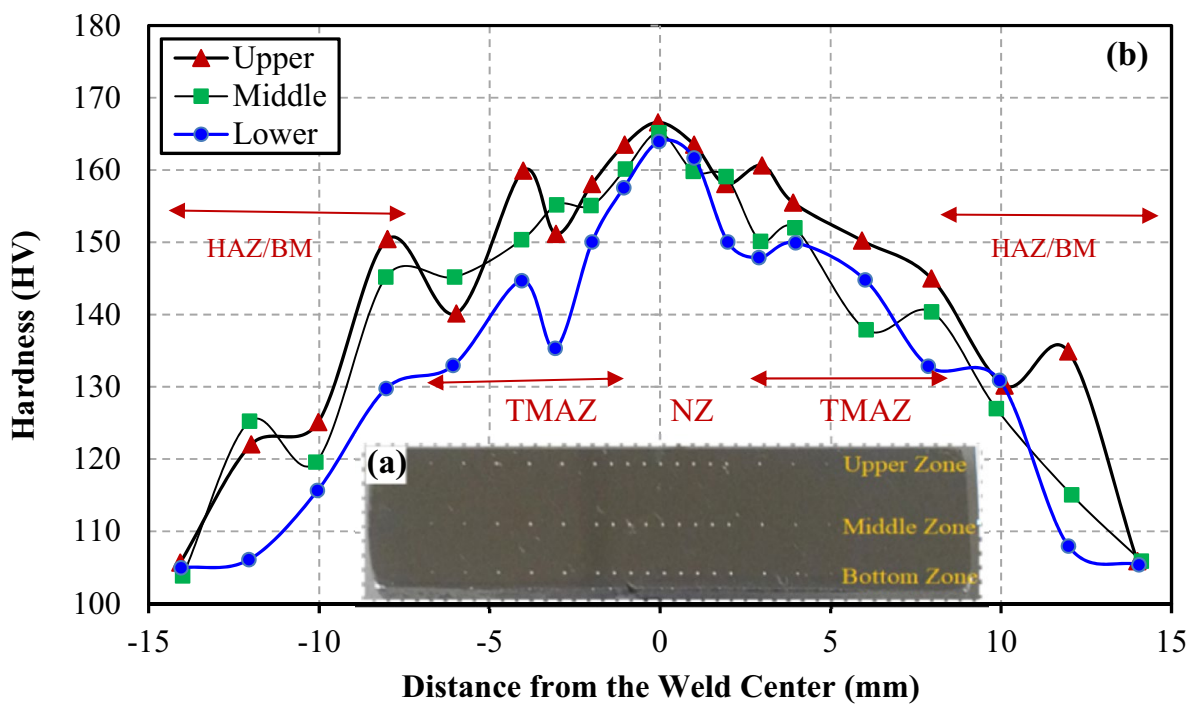

hardness increases. Hardness is the maximum at $24 \mathrm{~mm}$ shoulder diameter and a further increase in the value leads to grain growth due to higher heat generation and decreases the hardness. Plunge depth affects the variation in microhardness along the weld zones. The role of varying plunge depth at constant tool rotation speed and welding speed on the hardness value of the welded area was investigated and is represented in Fig. 8b. It is a critical parameter for heat generation and proper consolidation of plasticized metal without any defect. The plunge depth establishes proper contact with the shoulder workpiece interface as well as maintains the plung force required for welding. From the present investigation, hardness is the maximum at $0.06 \mathrm{~mm}$ plunge and degrades thereafter as the value increases. The reason behind this may be due to grain growth at more temperature generated due to excessive plunge. The tool pin profile effect on the hardness history of the weld specimen is represented in Fig. 8c. The SQ pin tool yields a noticeably higher hardness value as compared to the others. The design of the SQ profile imparts a positive result on the hardness by the repeated throbbing effect on the plasticized metal during the stirring process. The sharp edges of the SQ tool help in material ploughing, to better plasticize and swirl under the pin and well mix to fabricate the joint. Due to more plastic deformation and recrystallization in case of the SQ tool, the grains became finer [24] and the hardness is more.

The variation in hardness with varying tool rotation speed and welding speed at NZ was analyzed and is represented in Fig. $8 d$, e respectively. The variation in average micro-hardness value depends on the stirring action, which is a function of the rotation speed of the tool. If the rotational speed is low the hardness is less due to improper stirring resulting from insufficient heat generation. More is the rotational speed (up to a certain limit) of the tool higher is the stirring of plasticized material and more is the dynamic recrystallization, due to which the grain size is reduced, voids are decreased, grains are compacted, and finally, the hardness is improved. But at higher rotational speed (1100 rev/min), the tool deteriorates the strengthening effects of the alloy due to more stirring action and results in a decrease in hardness [27] as well as due to grain growth for excess temperature generated the hardness is declined. From the figure, it is analyzed that the hardness at NZ is highest at a tool rotational speed $815 \mathrm{rev} / \mathrm{min}$. A fall in the graph at higher tool rotational speed is observed due to the aforementioned cause. The measured hardness data as shown in Fig. 8e represents that lower welding speed gives rise to higher micro-hardness value as compared to the higher one as the exposure time for the weld to the temperature is more to get recrystallized. But after a certain extent, the hardness decreases due to overexposure to the temperature and grain growth [30] as shown in Fig. 8e. At lower welding speed, considering the tool rotational speed constant the hardness increases because of less pitch travel distance and finer grain.

\subsection{Metallographic study}

In this section microstructure of the welded joints was revealed through the optical microscope. The grain orientation and its size at various zones of the weld and the consequences of variation in process parameters on the grain size at NZ were analyzed. A detailed study on the mechanical property variation of the final weld with respect to the variation in grain size was also performed. 
Fig. 8 Variation of hardness at different process parameters, with a shoulder diameter, $\mathbf{b}$ plunge depth, $\mathbf{c}$ tool pin profile, $\mathbf{d}$ tool rotational speed and e welding speed
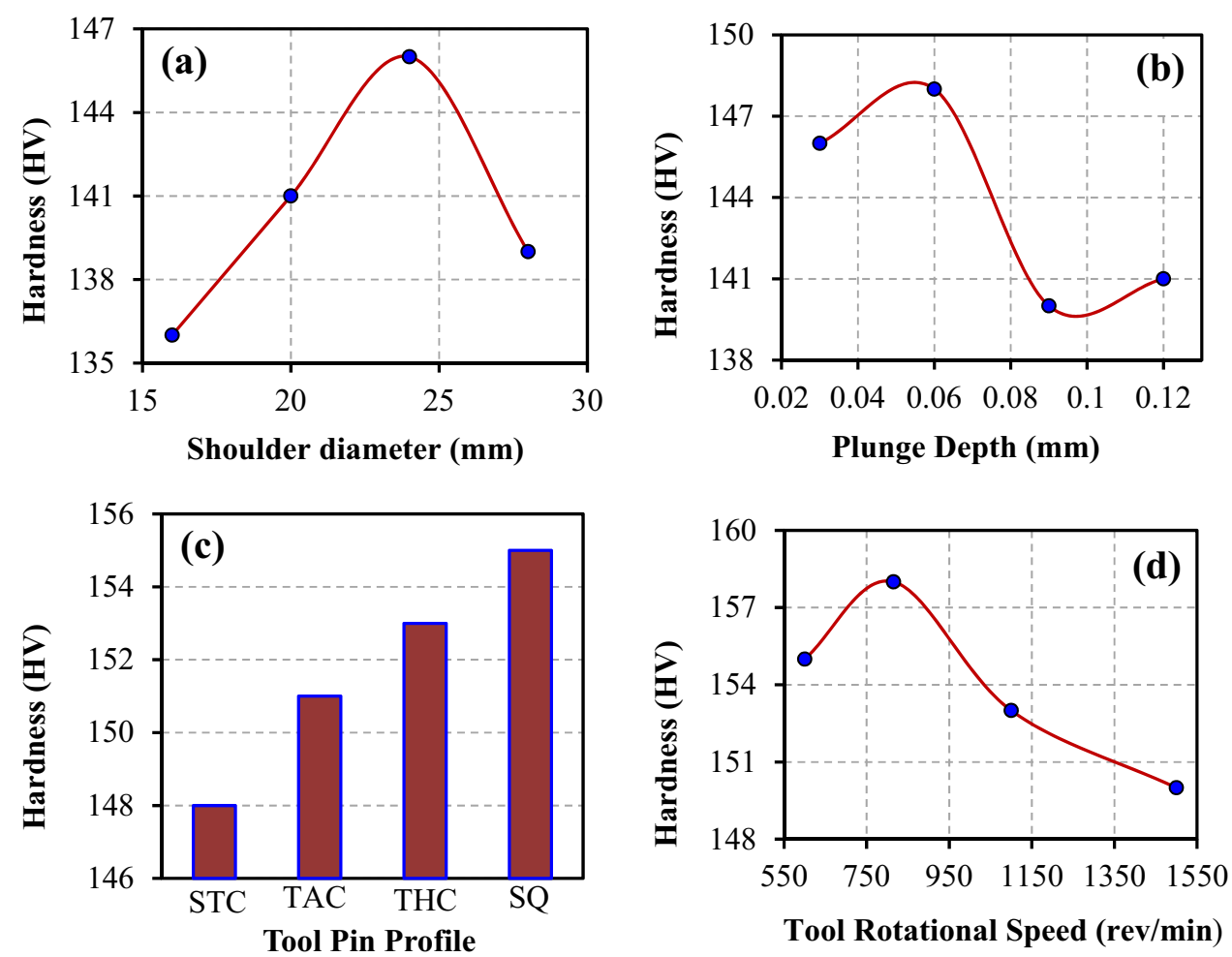

\subsubsection{Weld bead analysis}

The results of the microstructural investigation at various weld zones of the best (based on mechanical properties) experiment E15 was performed and are depicted in Fig. 9a. In the same figure the distinguished difference in grains at the weld zones viz. top and bottom of NZ, TMAZ and $H A Z$ are represented. The figure shows the transition line between the NZ/TMAZ as well as TMAZ/HAZ. However, the grain structure of $B M$ as well as advancing side and retreating side of TMAZ are revealed in Fig. 9b-d respectively. The microstructural study confirms that grains at the $\mathrm{NZ}$ are noticeably different compared to the other zones. This happened for the plastic deformation due to the stirring process of the tool pin and temperature generated during the friction. The coarser grains of BM became fine equiaxed at the NZ by recrystallization [31]. Through Heyn line intercept method [7] the average diameters of grain at various weld zones were measured and realized that the grains in NZ obtained by the severe stirring of the tool pin are finer than the grains in the other zones. For the combined effect of stirring process of the tool pin and repeated rubbing of the shoulder surface, the grains at the top of the NZ are finer compared to the bottom. The grains are also noticed to be like pulled out at the bottom owing to the repeated stirring of the tool pin. The average diameter of grains at the top of NZ is $15 \mu \mathrm{m}$ and is $84 \%$ finer than the BM grains of $97 \mu \mathrm{m}$. The modification in the grain structure at the NZ and the TMAZ is solely regulated by the thermal cycle and optimum temperature, which is an outcome of the process parameters setting. The grains in the advancing TMAZ $(33 \mu \mathrm{m})$ are finer than the grains in retreating TMAZ $(35 \mu \mathrm{m})$. The softened metal of TMAZ is extruded from the advancing side and swirled beneath the 
Fig. 9 a Weld bead micrograph with different weld zones, $\mathbf{b}$ base material, $\mathbf{c}$ advancing side $T M A Z$, d retreating side $T M A Z$

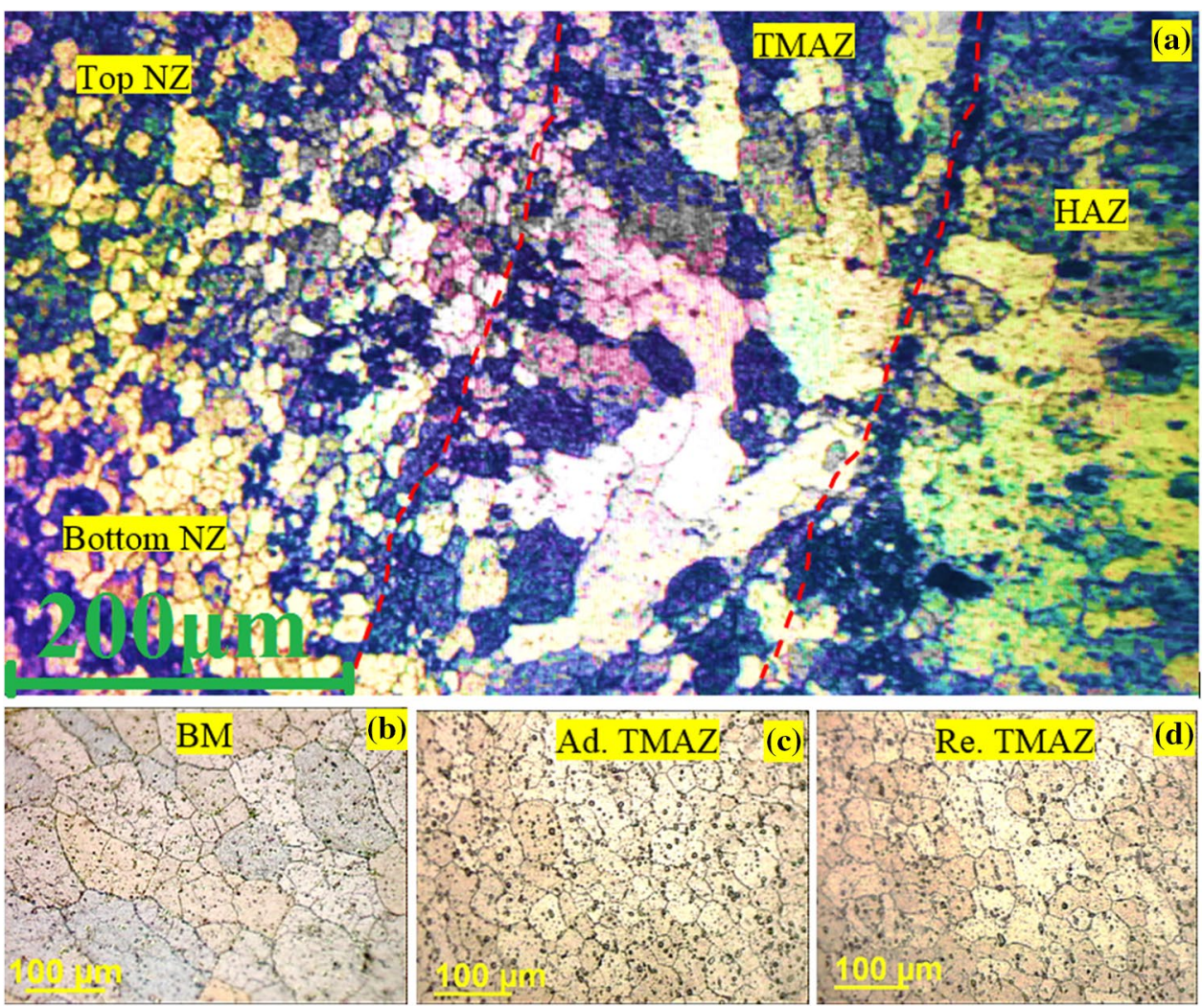

pin of the tool then deposited on the retreating side [32], and finally in the advancing side which encounters severe dynamic recrystallization and makes the grains comparatively finer than the retreating side TMAZ. The failure of tensile samples at the retreating side of TMAZ may be due to this reason as shown in Fig. 3f. From the optical micrographs, some grains in the TMAZ as presented in Fig. 9c, $d$ are understood to be pulled and elongated along the moving tool direction due to the shear force [7]. The effect of the tool in HAZ is less compared to other zones. Recrystallization never takes place in this zone, only a part of the frictional heat generated is conducted by the grains. The average grain size measured in this zone was $63 \mu \mathrm{m}$.

\subsubsection{Grains size variation at NZ with respect to process parameters}

The transition in average grain diameter at NZ with the considered process parameters for the experiment as represented in Table 3 was studied in this section and is depicted in Fig. 10. The grains size variations with respect to the variation in shoulder diameters from 16 to $28 \mathrm{~mm}$ are shown in Fig. 10a-d. As the diameter increases the tool workpiece contact area is increased which leads to a larger frictional surface. So higher frictional heat is produced and is conducted to the material beneath the shoulder. This frictional heat is added to the heat developed by the tool pin during the stirring [3] in better plasticizing and for proper mixing. As a result, the material gets recrystallized and grains became finer. From the experimental result, the shoulder diameter $24 \mathrm{~mm}$ produces finer grains of $23 \mu \mathrm{m}$ at the NZ as shown in Fig. 10c. Due to the finer grains hardness and tensile properties of the welded joint are superb. In other cases, i.e. at lower shoulder diameter due to inadequate frictional heat, the inferior grains were achieved. At higher shoulder diameter, i.e. at $28 \mathrm{~mm}$, the grain growth occurs due to excessive heat which yields a low quality weld.

With the variation in plunge depth, the grain size also varies and hence, the mechanical properties. At a plunge depth of $0.03 \mathrm{~mm}$, the average grain size is $23 \mu \mathrm{m}$ shown in Fig. 10c. At a plunge depth of $0.06 \mathrm{~mm}$, average grain size is lower and is $21 \mu \mathrm{m}$ as in Fig. 10e. Finer grains were obtained in this case due to optimum heat transfer [3]. At a plunge depth more than $0.06 \mathrm{~mm}$ heat generation is excessive which leads to grain growth. The design of the tool pin profile affects the grain size variation at NZ to a great extent. From the experimental results and microstructural analysis, the best tensile, flexural and microstructural properties were acquired from the SQ tool due to the unique material transportation and imposed plastic deformation as discussed in the earlier section. The grain developed at NZ of the SQ pin was compared with the STC pin based on mechanical 

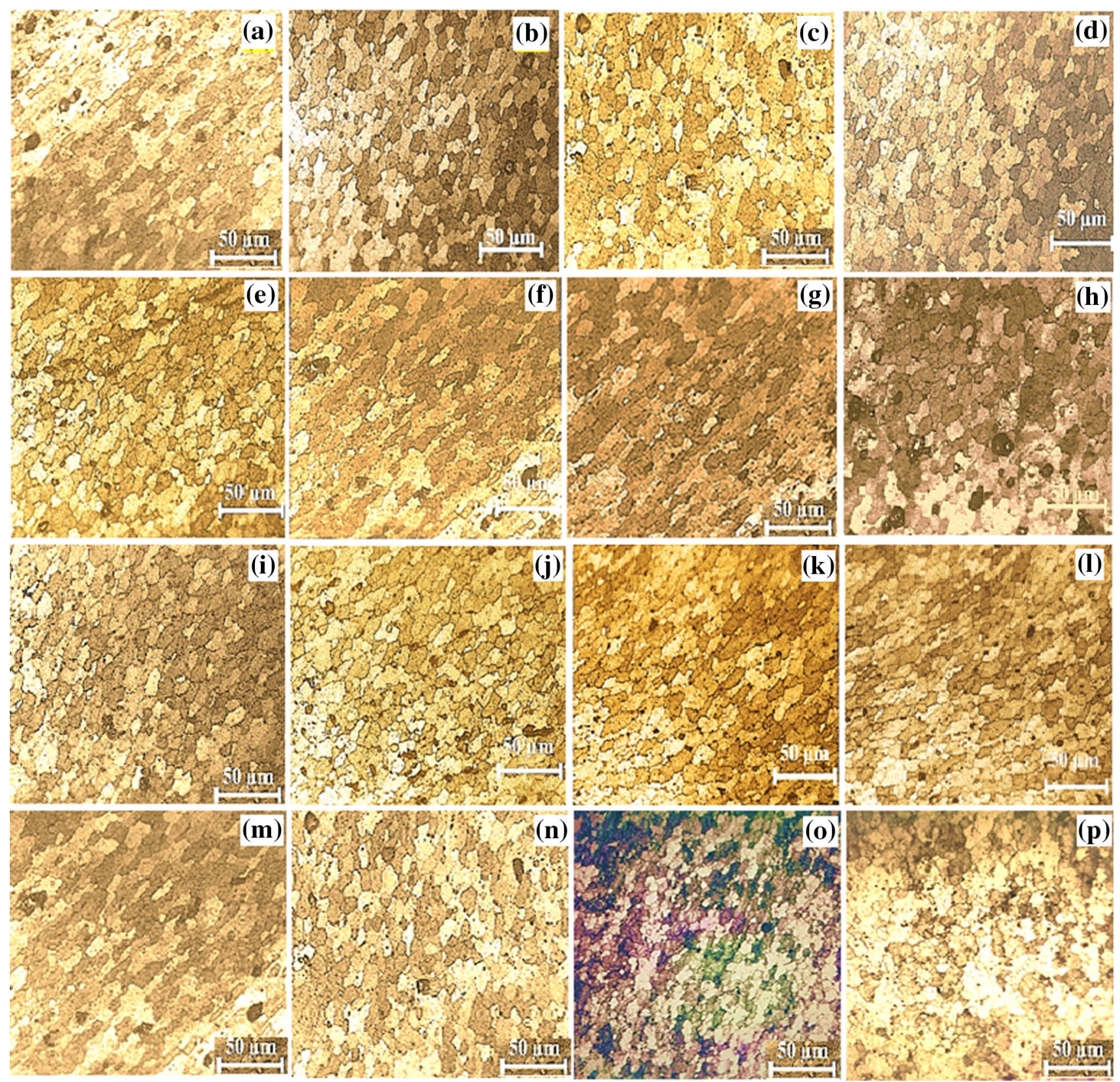

Fig. 10 Grain size variation with respecte to the process parameters, a-d shoulder diamater, $\mathbf{c}, \mathbf{e}-\mathbf{g}$ plunge depth, $\mathbf{e}, \mathbf{h}-\mathbf{j}$ tool pin profile, $\mathbf{j}-\mathbf{m}$ tool totational speed and $\mathbf{k}, \mathbf{n}-\mathbf{p}$ welding speed

properties obtained. The superior properties of the SQ is due to the smaller grain of $18 \mu \mathrm{m}$ at the NZ as presented in Fig. 10j than the STC grain of $21 \mu \mathrm{m}$ size at NZ shown in Fig. 10e. The same trend was repeated in case of welds done with parameters welding speed as well as tool rotation speed. There is declination in average grain size at NZ with a decline in welding speed and rise in tool rotation speed was noticed. It is found that the grain size variation depends on the ratio between the tool rotational speed and welding speed [27]. At higher ratio (lower welding speed) grains are finer due to heat input per unit length is higher. At a higher ratio (high tool rotation speed) of $1100 \mathrm{rev} / \mathrm{min}$ and $1500 \mathrm{rev} /$ min, finer grains were achieved, but tensile properties decreased significantly for local thinning due to flash formation. A comparison of the grain size at the NZ was established in case of $600 \mathrm{rev} / \mathrm{min}$ and $815 \mathrm{rev} / \mathrm{min}$ tool rotational speed as given in Fig. 10j, k respectively. The grains developed at $815 \mathrm{rev} / \mathrm{min}$ were $17 \mu \mathrm{m}$ and are finer than the grains developed at $600 \mathrm{rev} / \mathrm{min}$ of $18 \mu \mathrm{m}$

\section{SN Applied Sciences}



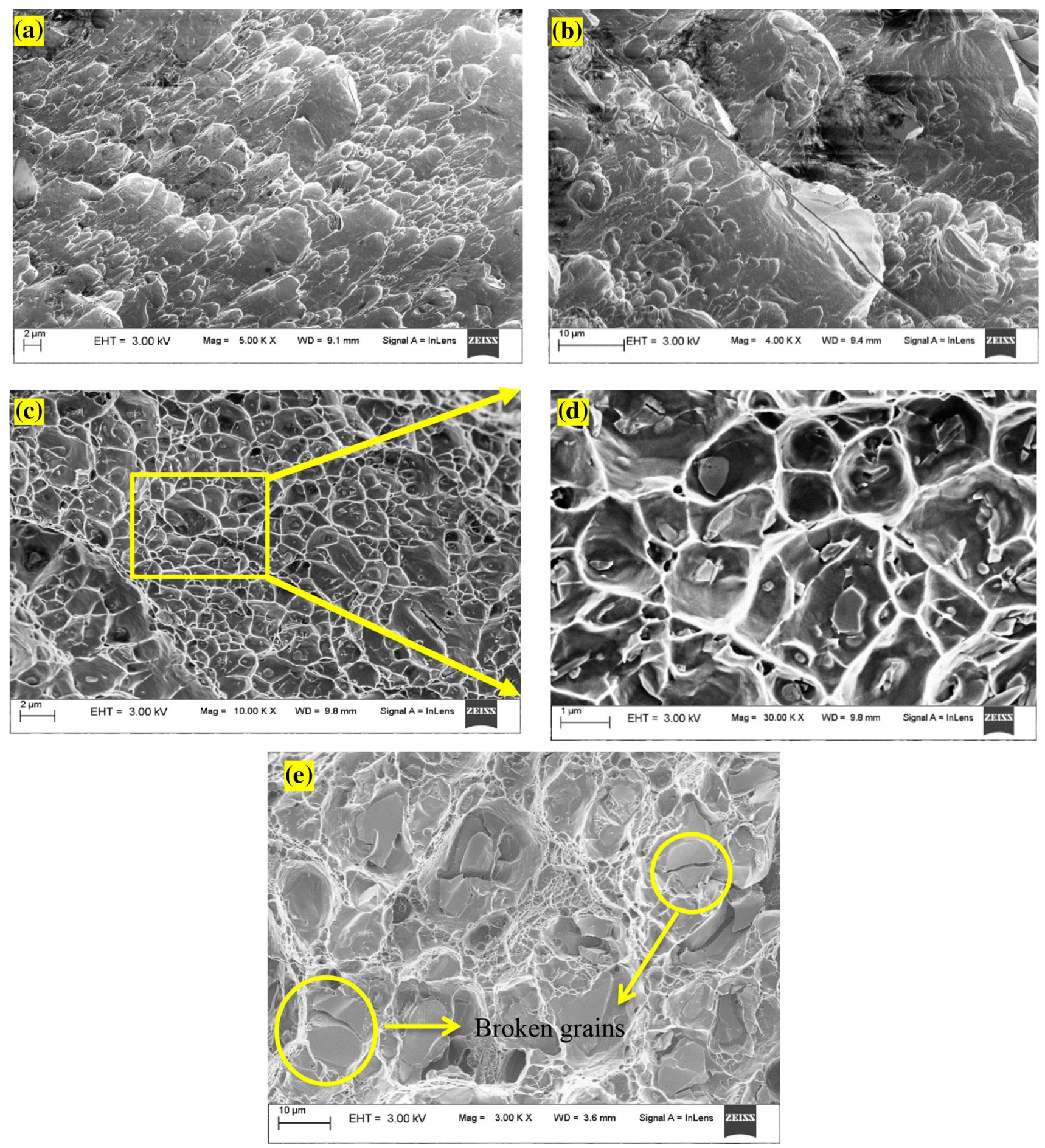

Fig. 11 FESEM fractograph image of different tensile tested fractured surfaces a specimen E15, b specimen E3, c specimen E1, d enlarged view of specimen $\mathrm{E} 1$, e specimen $\mathrm{E} 12$

size. The grain size obtained was $17 \mu \mathrm{m}$ at a welding speed of $22 \mathrm{~mm} / \mathrm{min}$ and $15 \mu \mathrm{m}$ at $63 \mathrm{~mm} / \mathrm{min}$ as shown in Fig. 10 k, o respectively.

\subsection{Fractograph analysis}

Some of the tensile tested fractured samples are presented in Fig. 3. The fracture location varies according to the quality of the welds which is a function of the 
process parameters chosen as described in the previous section. The fracture located outside the weld zone for the best quality welds as presented in Fig. $3 a-c$ and the fractographic analysis through FESEM of the specimen E15 experiment is similar to the BM as shown in Fig. 11a. The figure depicts a pure ductile mode of fracture because it shows a dimple shaped cup and cone envelop on the fractograph. This feature on the fracture interface indicates more bonding energy and ductility as observed in the mechanical analysis. The ductile failure of the experimented AA is for the FCC (face centered cubic) lattice structure with an incorporation of a very large number of active slip systems. However, Fig. $11 \mathrm{~b}$ indicates the tensile fractured specimen of E3 with less ductile features and the fracture happened at the interface of TMAZ/HAZ. The fracture started as an indicated crack line and propagated towards TMAZ. It includes similar features of E15, but fewer dimples indicating lower ductility for the stirring influence of the tool pin. Large dimples observed in the figure have a great role in crack propagation and decreased strength. This less ductility in case of $\mathrm{E} 3$ also indicates the less tensile properties compared to E15.

In some of the experiments namely E1-2, E6-7, the fracture arose within the FSW joint area is also resembled the combination of ductile as well as brittle fracture mode. The feature of the fracture surface also includes the river like patterns and feather markings as found in Fig. $11 \mathrm{c}$ and its magnified view in Fig. $11 \mathrm{~d}$. The combination of ductile as well as brittle mode fracture starts dislocations movement at NZ. For most of the specimens with less tensile strength, a combination of ductile plus brittle mode fracture is observed at NZ which is also named as "quasi-cleavage" fracture [33] where voids without metallurgical bonds were also observed that lowers the strength. In some other experiments like E12-E13, the fracture occurred at TMAZ as revealed in Fig. 11e because of the variation in grain size. This type of fracture consists of intergranular fracture indicating the fracture line through the grain interface and as a result, some broken grains are also observed as indicated in the same Fig. 11e. The broken grains are not in regular shape and leads to inferior weld strength compared to E15.

\section{Conclusion}

From the obtained results the conclusions extracted are summarized below.

- FSW process is a suitable method to join AA 2014 of $6 \mathrm{~mm}$ thickness plate with a modified vertical mill- ing machine with full penetration which yielded zero-defect joints by a $24 \mathrm{~mm}$ shoulder diameter SQ tool with $0.06 \mathrm{~mm}$ plunge depth at $815 \mathrm{rev} / \mathrm{min}$ tool rotational speed and $63 \mathrm{~mm} / \mathrm{min}$ welding speed. The excellency of the joint is justified by the UTS and FS values which are $86 \%$ and $90 \%$ of the BM respectively. The microstructural feature is found to be the best with outstanding metallurgical characteristics contributed by the grains which are $84 \%$ finer than the BM.

- Hardness profile of the FSWed specimen along the thickness represents an inverted $V$ shape with the maximum value at NZ and the lowest at HAZ. The hardness measured at the upper zone of the joint is the highest than the middle and lower zone.

- The metallurgical transformation at the NZ was revealed individually with respect to the considered process parameters by studying the grain size variation.

cknowledgements The present research work was supported by the Mechanical Engineering Department and the Central Instruments Facility, Indian Institute of Technology Guwahati, for availing facilities to conduct experiments and testing.

\section{Compliance with ethical standards}

Conflict of interest The authors declare that they have no conflict of interest.

Human and animal rights This research work was performed by human only and no involvement of any animal.

\section{References}

1. Thomas WM, Nicholas ED, Needham JC (1991) Friction stir welding. International Patent Application No. PCT/GB92/02203 and Great Britain Patent Application No. 9125978.8.

2. Amancio-Filhoa ST, Sheikhi S, dos Santos JF, Bolfarini C (2008) Preliminary study on the microstructure and mechanicalproperties of dissimilar friction stir welds in aircraft aluminium alloys 2024-T351 and 6056-T4. J Mater Process Technol 206:132-142. https://doi.org/10.1016/j.jmatprotec.2007.12.008

3. Sahu PK, Pal S (2017) Influence of metallic foil alloying by FSW process on mechanical properties and metallurgical characterization of AM20 Mg alloy. Mater Sci Eng A 684:442-455. https://doi.org/10.1016/j.msea.2016.12.081

4. Mishra RS, Ma ZY (2005) Friction stir welding and processing. Mater Sci Eng R 50:1-78. https://doi.org/10.1016/j. mser.2005.07.001

5. Kadaganchi R, Gankidi MR, Gokhale H (2015) Optimization of process parameters of aluminum alloy AA 2014-T6 friction stir welds by response surface methodology. Defence Technol 11:209-219. https://doi.org/10.1016/j.dt.2015.03.003

6. Tutunchilar S, Haghpanahi M, Besharati Givi MK, Asadi P, Bahemmat $P$ (2012) Simulation of material flow in friction stirs 
processing of a cast Al-Si alloy. Mater Des 40:415-426. https:// doi.org/10.1016/j.matdes.2012.04.001

7. Sahu PK, Pal S, Pal SK, Jain R (2016) Influence of plate position, tool offset and tool rotational speed on mechanical properties and microstructures of dissimilar $\mathrm{Al} / \mathrm{Cu}$ friction stir welding joints. J Mater Process Technol 235:55-67. https://doi. org/10.1016/j.jmatprotec.2016.04.014

8. Cavaliere P, Campanile G, Panella F, Squillace A (2006) Effect of welding parameters on mechanical and microstructural properties of AA6056 joints produced by friction stir welding. J Mater Process Technol 180:263-270. https://doi.org/10.1016/j.jmatp rotec.2006.06.015

9. Bertrand R, Robe $H$, Texier $D$, Zedan $Y$, Feulvarch $E$, Bocher $P$ (2019) Analysis of AA2XXX/AA7XXX friction stir welds. J Mater Process Technol 271:312-324. https://doi.org/10.1016/j.jmatp rotec.2019.03.027

10. Sinhmar S, Dwivedi DK (2019) Effect of weld thermal cycle on metallurgical and corrosion behavior of friction stir weld joint of AA2014 aluminium alloy. J Manuf Process 37:305-320. https ://doi.org/10.1016/j.jmapro.2018.12.001

11. Ahmed MMZ, Wynne BP, Rainforth WM, Addison A, Martin JP, Threadgill PL (2019) Effect of tool geometry and heat input on the hardness, grain structure, and crystallographic texture of thick-section friction stir-welded aluminium. Metall Mater Trans A Phys Metall Mater Sci 50:271-284. https://doi.org/10.1007/ s11661-018-4996-2

12. Huang Y, Xie Y, Meng X, Lv Z, Cao J (2018) Numerical design of high depth-to-width ratio friction stir welding. J Mater Process Technol 252:233-241. https://doi.org/10.1016/j.jmatprotec 2017.09.029

13. Khalilabad MM, Zedan Y, Texier D, Jahazi M, Bocher P (2018) Effect of tool geometry and welding speed on mechanical properties of dissimilar AA2198-AA2024 FSWed joint. J Manuf Process 34:86-95. https://doi.org/10.1016/j.jmapro.2018.05.030

14. Mastanaiah P, Sharma A, Reddy GM (2018) Role of hybrid tool pin profile on enhancing welding speed and mechanical properties of AA2219-T6 friction stir welds. J Mater Process Technol 257:257-269. https://doi.org/10.1016/j.jmatprotec.2018.03.002

15. Khan NZ, Siddiquee AN, Khan ZA, Mukhopadhya AK (2017) Mechanical and microstructural behavior of friction stir welded similar and dissimilar sheets of AA2219 and AA7475 aluminium alloys. J Alloys Compd 695:2902-2908. https://doi.org/10.1016/j. jallcom.2016.11.389

16. Sun T, Roy MJ, Strong D, Withers PJ, Prangnell PB (2017) Comparison of residual stress distributions in conventional and stationary shoulder high-strength aluminum alloy friction stir welds. J Mater Process Technol 242:92-100. https://doi.org/10.1016/j. jmatprotec.2016.11.015

17. Wu H, Chen YC, Strong D, Prangnell P (2015) Stationary shoulder FSW for joining high strength aluminum alloys. J Mater Process Technol 221:187-196. https://doi.org/10.1016/j.jmatprotec .2015.02.015

18. Saravanan V, Rajakumar S, Banerjee N, Amuthakkannan R (2016) Effect of shoulder diameter to pin diameter ratio on microstructure and mechanical properties of dissimilar friction stir welded AA2024-T6 and AA7075-T6 aluminum alloy joints. Int J Adv Manuf Technol 87:3637-3645. https://doi.org/10.1007/s0017 0-016-8695-0

19. Luo C, Li X, Song D, Zhou N, Li Y, Qi W (2016) Microstructure evolution and mechanical properties of friction stir welded dissimilar joints of $\mathrm{Mg}-\mathrm{Zn}-\mathrm{Gd}$ and $\mathrm{Mg}-\mathrm{Al}-\mathrm{Zn}$ alloys. Mater Sci Eng A 664:103-113. https://doi.org/10.1016/j.msea.2016.03.117
20. Trimble D, O Donnell GE, Monaghan J (2015) Characterization of tool shape and rotational speed for increased speed during friction stir welding of AA2024-T3. J Manuf Process 17:141-150. https://doi.org/10.1016/j.jmapro.2014.08.007

21. Rajesh Jesudoss Hynes N, Shenbaga Velu P (2018) Effect of rotational speed on Ti-6Al-4V-AA 6061 friction welded joints. J Manuf Process 32:288-297. https://doi.org/10.1016/j.jmapr o.2018.02.014

22. Liu HJ, Fujii H, Maeda M, Nogi K (2003) Tensile properties and fracture locations of friction-stir-welded joints of 2017-T351 aluminum alloy. J Mater Process Technol 142:692-696. https://doi. org/10.1016/S0924-0136(03)00806

23. Peel M, Steuwer A, Preuss M, Withers PJ (2003) Microstructure, mechanical properties and residual stresses as a function of welding speed in aluminium AA5083 friction stir welds. Acta Mater 51:4791-4801. https://doi.org/10.1016/S1359 -6454(03)00319-7

24. Jamalian HM, Farahani M, Givi BMK, Vafaei AM (2016) Study on the effects of friction stir welding process parameters on the microstructure and mechanical properties of $5086-\mathrm{H} 34$ aluminum welded joints. Int J Adv Manuf Technol 83:611-621. https://doi.org/10.1007/s00170-015-7581-5

25. Liu HJ, Hou JC, Guo H (2013) Effect of welding speed on microstructure and mechanical properties of self-reacting friction stir welded 6061-T6 aluminum alloy. Mater Des 50:872-878. https ://doi.org/10.1016/j.matdes.2013.03.105

26. Moradi MM, Aval HJ, Jamaati R, Amirkhanlou S, Ji S (2018) Microstructure and texture evolution of friction stir welded dissimilaraluminum alloys: AA2024 and AA6061. J Manuf Process 32:1-10. https://doi.org/10.1016/j.jmapro.2018.01.016

27. Malika V, Sanjeev NK, Hebbar HS, Kailas VS (2014) Investigations on the effect of various tool pin profiles in friction stir welding using finite element simulations. Procedia Eng 97:1060-1068. https://doi.org/10.1016/j.proeng.2014.12.384

28. Salari E, Jahazi M, Khodabandeh A, Ghasemi-Nanesa H (2014) Influence of tool geometry and rotational speed on mechanical properties and defect formation in friction stir lap welded 5456 aluminum alloy sheets. Mater Des 58:381-389. https://doi. org/10.1016/j.matdes.2014.02.005

29. Kwon YJ, Shim SB, Park DH (2009) Friction stir welding of 5052 aluminum alloy plates. Trans Nonferr Met Soc China 19:s23-s27. https://doi.org/10.1016/S1003-6326(10)60239-7

30. Kumbhar NT, Sahoo SK, Samajdar I, Dey GK, Bhanumurthy K (2011) Microstructure and micro textural studies of friction stir welded aluminium alloy 5052. Mater Des 32:1657-1666. https ://doi.org/10.1016/j.matdes.2010.10.010

31. Bocchi S, Cabrini M, Dursoa G, Giardini C, Lorenzi S, Pastore T (2018) The influence of process parameters on mechanical properties and corrosion behavior of friction stir welded aluminum joints. J Manuf Process 35:1-15. https://doi.org/10.1016/j.jmapr o.2018.07.012

32. He X, Gu F, Ball A (2014) A review of numerical analysis of friction stir welding. Prog Mater Sci 65:1-66. https://doi.org/10.1016/j. pmatsci.2014.03.003

33. Sahu PK, Pal S (2017) Mechanical properties of dissimilar thickness aluminium alloy weld by single/double pass FSW. J Mater Process Technol 243:442-455. https://doi.org/10.1016/j.jmatp rotec. 2017.01.009

Publisher's Note Springer Nature remains neutral with regard to jurisdictional claims in published maps and institutional affiliations. 